\section{Dangerous Consequence from Use of Phenytoin in Atrial Flutter}

\section{Brit. med. F., 1967, 4, 34}

Phenytoin sodium (Epanutin)* has been used successfully in various ventricular and supraventricular arrhythmias (Leonard, 1958 ; Dreifus et al., 1964 ; Conn, 1965) and has been recommended for the treatment of digitalis-induced tachycardias (Conn, 1965 ; Lang et al., 1965 ; Ruthen, 1965 ; Smith, 1966). It would therefore appear to be a suitable drug for patients who require immediate termination of a rapid arrhythmia in the face of an unclear history of digitalis, diuretic, and potassium intake. For this reason we wish to record a dangerous complication of this drug-namely, the conversion of paroxysmal atrial flutter with $2: 1$ block to $1: 1$ conduction with a ventricular rate of 300 per minute. The decision to use phenytoin was made because this patient was in acute pulmonary oedema and required urgent treatment; she had been treated for many years with digitoxin and a thiazide diuretic without potassium supplements, and digitalis intoxication could not be excluded.

\section{CASE Report}

A 38-year-old Negro woman with chronic rheumatic heart disease was admitted to Cook County Hospital in acute pulmonary oedema.

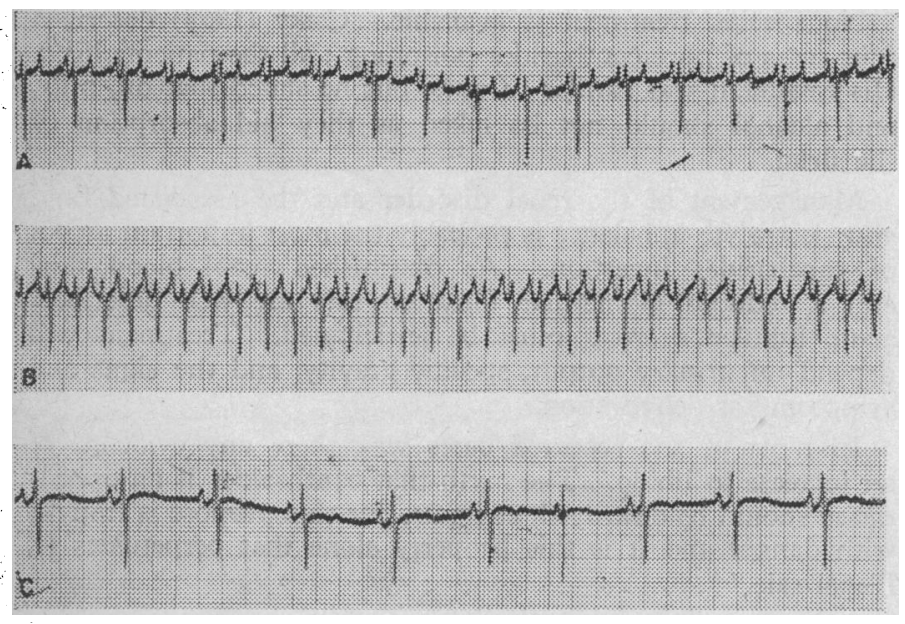

Electrocardiographic tracing showing paroxysmal atrial flutter with 2:1 conduction (A). The administration of phenytoin led to the establishment of $1: 1$ conduction with a ventricular rate of 300 a minute $(B)$. The patient later reverted to sinus rhythm after administration of digitalis (C).

She had had a mitral commissurotomy nine years before admission; in recent years symptoms recurred and she had become progressively incapacitated by exertional dyspnoea. One day before admission she developed palpitations, haemoptysis, and severe breathlessness at rest. She had been treated with digitoxin $0.1 \mathrm{mg}$. a day, thiazide diuretics, but no potassium supplements up to the day of her admission.

Physical examination revealed a woman in acute distress. The pulse rate was 150 a minute and was not affected by carotid sinus pressure. Blood pressure was $110 / 80 \mathrm{~mm}$. $\mathrm{Hg}$. The heart was not enlarged, but she had the physical signs of mitral valve disease and pulmonary oedema. An electrocardiogram showed atrial flutter at a

* Known in U.S.A. as diphenylhydantoin sodium (Dilantin). rate of 300 and a ventricular rate of 150 , with a $2: 1$ atrioventricular block (see Fig.).

With electrocardiographic monitoring a slow intravenous injection of phenytoin sodium was begun. After two minutes, when approximately $150 \mathrm{mg}$. had been injected, the heart rate increased to 300 and $1: 1$ conduction was observed. Deslanoside (Cedilanid) $0.4 \mathrm{mg}$. was given intravenously and after five minutes she reverted back to her previous rhythm. An additional $0.4 \mathrm{mg}$. of deslanoside was subsequently given and she converted to sinus rhythm at a rate of 78. The serum potassium level at the time of admission was later reported to be $3.8 \mathrm{mEq} / \mathrm{l}$.

Clinical evaluation at a slow heart rate revealed signs of tight mitral stenosis. The results of cardiac catheterization in February 1965 were later obtained; the mitral valve area was $0.6 \mathrm{sq} . \mathrm{cm}$. Operation was refused at that time.

\section{COMMENT}

Phenytoin, while effective in stopping aconitine-induced atrial flutter in experimental animals, has been found to be generally ineffective in treatment of this arrhythmia in man (Conn, 1965 ; Ruthen, 1965). Nevertheless, Friedberg (1966) has referred to one patient in whom the drug may have been effective in converting atrial flutter to sinus rhythm. Our patient was in acute distress due to pulmonary oedema; and the possibility of digitalis intoxication, though rarely presenting as atrial flutter, was seriously considered; hence the decision to give intravenous phenytoin. The patient responded by the establishment of $1: 1$ conduction with an extremely rapid heart rate.

The mechanism of action of phenytoin in cardiac arrhythmias is not clear. Evidence has been presented that it decreases intracellular sodium content in cardiac muscle (Dreifus et al., 1964 ; Ruthen, 1965). Clinically, the action of phenytoin is similar to that of quinidine and antazoline-that is, depression of excitability, conductivity, and contractility of cardiac muscle (Friedberg, 1966). Production of 1:1 conduction has been reported with both quinidine and antazoline (Dreifus et al., 1964) and perhaps might also be expected to occur with phenytoin. We believe that the above case shows that intravenous phenytoin should not be used in atrial flutter with block, unless there is overwhelming evidence of digitalis intoxication.

James H. Grissom, M.D.,

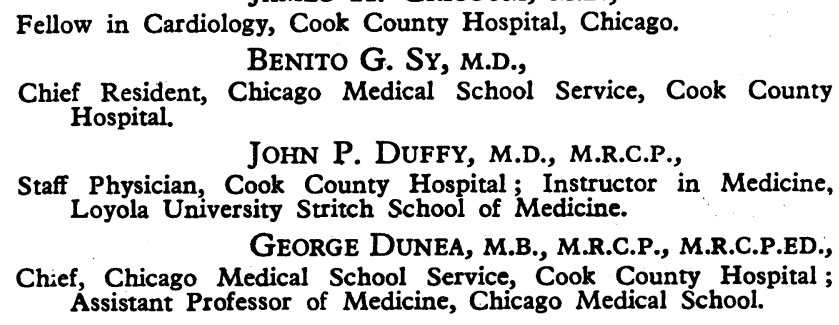

GEORGE DUNEA, M.B., M.R.C.P., M.R.C.P.ED.,

Chief, Chicago Medical School Service, Cook County Hospital ; Assistant Professor of Medicine, Chicago Medical School.

\section{REFERENCES}

Conn, R. D. (1965). New Engl. F. Med., 272, 277.

Dreifus, L. S., Rabbino, M. D., and Watanabe, Y. (1964). Med. Clin. N. Amer., 48, 371.

Friedberg, C. K. (1966). Diseases of the Heart, 3rd ed., pp. 510, 533.

Lang, T. W., Bernstein, H., Barbieri, F., Gold, H., and Corday, E. (1965). Arch. intern. Med., 116, 573 ."

Leonard, W. A., jun. (1958). Ibid., 101, 714.

Ruthen, G. C. (1965). Amer. Heart F., 70, 275.

Smith, W. G. (1966). Brit. med. F., 2, 113. 